\title{
Socio-demographic, injury-related and pre-injury job characteristics associated with return to work outcome among injured worker in South Korea
}

\author{
Park, Soo Kyung Lee, Chun Kwon Lee, Sung Min \\ Graduate school of Social Welfare, Yonsei University
}

\begin{abstract}
The identification of the potential determinants would be helpful in improving return to work (RTW) rate following injury. The aim of this study is to examine the associations between RTW outcomes and demographic, injury-related, and pre-injury job characteristics among injured workers in South Korea. This study employed the first wave data from the Panel Study of Worker's Compensation Insurance, and the sample were 1,993 injured workers in 2012. Two-step cluster analysis was carried out to profile pre-injury job characteristics including average monthly wage, work period, the number of employees, contract type, and working hours in the pre-injury firm. Multinomial logistic regression was conducted to examine the associations between return to work outcomes and socio-demographic, injury related, and pre-injury job characteristics. Two clusters were identified: Injured workers $(n=995,49.9 \%)$ profiled in the first cluster were more likely than those of the second cluster $(\mathrm{n}=998,50.1 \%)$ to be parttime workers with lower wages and shorter work periods in small sized companies. Workers in the second cluster were more likely than those of the first cluster to return to pre-injury jobs, compared to unemployed. Compared to unmarried and women, workers who were married and men were more likely to have better return to work outcomes; young workers who had good health, short duration of medical care benefits and good ability to work after medical care services were more likely to return to pre-injury jobs or work at a new firm than unemployed. These findings demonstrated that special attention needs to be directed to not only demographic and injury-related but also pre-injury job characteristics when designing RTW programs for injured workers in South Korea.
\end{abstract}

Keyword- Return to work, Injured workers, Pre-injury, Pre-injury job characteristics, vocational rehabilitation, Two-step cluster analysis 